\title{
DISTRIBUIÇÃO ESPAÇO-TEMPORAL DAS CAPTURAS ACIDENTAIS DE TONINHAS (Pontoporia blainvillei) EM REDES DE EMALHE E DOS ENCALHES AO LONGO DA COSTA SUL DO RIO GRANDE SUL, BRASIL
}

\author{
EMANUEL CARVALHO FERREIRA; MÔNICA M. C. MUELBERT; EDUARDO RESENDE SECCHI \\ Universidade Federal do Rio Grande - FURG. Instituto de Oceanografia, Programa de Pós-graduação em Oceanografia Biológica; Av. Itália, \\ km 8, Caixa Postal 474; CEP-96201-900; Rio Grande - RS, Brasil. emanuelferreira@furg.br
}

\begin{abstract}
O presente estudo visa descrever os padrões espaço-temporais das capturas acidentais e encalhes de toninhas, Pontoporia blainvillei, bem como dos lances de pesca da frota comercial de emalhe que opera na costa centro-sul do Rio Grande do Sul. A pesca comercial costeira de emalhe, nesta região é responsável por uma elevada captura acidental da espécie. Foram analisados 690 lances de pesca feitos por 23 embarcações, sendo 136 capturas acidentais e 348 encalhes coletados entre janeiro de 2002 e dezembro de 2003. Estes dados foram plotados em mapas sazonais georeferenciados agrupados em células de $20 \times 20 \mathrm{~km}$. Existem mudanças sazonais e interanuais nas áreas preferenciais de pesca, contudo estas estão amplamente distribuídas na plataforma interna do centro-sul do Rio Grande do Sul. Entretanto, a taxa de capturas acidentais foi maior entre o Chuí e o farol Albardão ( $K W=13,958, g l=5, p=0,01)$. E existe uma correlação forte entre a taxa de encalhe e o vento $\left(r_{s}, r=-0,73 ; p<0,05\right)$.
\end{abstract}

RESUMO

PALAVRAS CHAVE: Captura acidental, encalhe, Pontoporia blainvillei, conservação, distribuição espaço-temporal

\section{ABSTRACT}

SPATIO-TEMPORAL DISTRIBUTION OF FRANCISCANA (Pontoporia blainvillei) BYCATCH IN THE COASTAL GILLNET FISHERIES OPERATING AND STRANDINGS ALONG THE COAST OF RIO GRANDE DO SUL, BRAZIL

This study aims to describe spatio-temporal patterns in bycatch and strandings of franciscanas, Pontoporia blainvillei, as well as of net settings of the coastal commercial gillnetting fleet operating off central and southern Rio Grande do Sul coast. This commercial gillneting fleet is responsible for high incidental takes of the species. A total of 690 net settings made by 23 fishing boats resulted in 136 bycatches from January 2002 to December 2003. For the same period 348 strandings were recorded. These data were plotted in georeferenced maps, split in $20 \times 20 \mathrm{~km}$ grids for each season. Despite some seasonal and year-toyear variation in preferential fishings areas, they are widely distributed in the inner continental shelf off central-southern Rio Grande do Sul. Nevertheless, the bycatch rate was higher between Chui and Albardão lighthouse $(K W=13.958, g l=5, p=0.01)$. And there is a strong correlation between strandings and wind force $\left(r_{s}, r=-0,73 ; p<0,05\right)$.

KEI WORDS: Bycatch, strandings, Pontoporia blainvillei, conservation, spatio-temporal distribution

\section{INTRODUÇÃO}

A toninha, Pontoporia blainvillei (Cetacea, Pontoporiidae) tem distribuição restrita às águas costeiras do Oceano Atlântico Sul Ocidental e é encontrada desde Itaúnas (1825’S), Espírito Santo, Brasil (Siciliano 1994), até o Golfo San Mathias

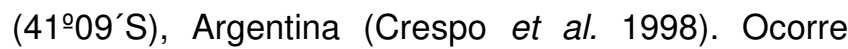
principalmente em águas abaixo da isóbata de $30 \mathrm{~m}$ (Secchi \& Ott 2000). O hábito costeiro da toninha potencializa a alta freqüência de capturas acidentais nos locais de pesca situados próximos à costa, principalmente em redes de emalhe, ao longo da sua distribuição (e.g. Praderi et al. 1989, Corcuera et al. 1994, Di Beneditto \& Ramos, 2001, Bertozzi \& Zerbini 2002, Secchi et al. 1997, 2003a). No Brasil as capturas ocorrem o ano inteiro (Ott et al. 2002, Secchi et al. 2003a) enquanto na Argentina e no Uruguai, a maioria das toninhas é capturada na primavera e no verão (Corcuera et al. 1994, Praderi 1997).

No Rio Grande do Sul, estudos sobre a mortalidade de toninhas iniciaram em meados da década de 1970 através do registro do número de indivíduos encontrados encalhados na praia durante monitoramentos sistemáticos. Considerando estes dados, 1076 toninhas foram encontradas encalhadas entre 1979 e 1998, na costa do Rio Grande do Sul (Pinedo \& Polacheck 1999). No início da década de 90 iniciou-se o monitoramento da frota costeira de emalhe do Rio Grande do Sul, onde dados de capturas acidentais de toninhas vêm sendo sistematicamente coletados (Secchi et al. 1997, 2006). A estimativa anual de mortalidade para o litoral norte do Rio Grande do Sul é de aproximadamente 500 animais (Moreno et al. 1997, Ott et al. 2002), enquanto que para o litoral sul estes valores podem ser bem mais elevados (Secchi et al. 2003a). Secchi et al. (2001) obtiveram a primeira estimativa de abundância de toninhas para a região do Rio Grande do Sul e do Uruguai, apartir de dados de sobrevôo, estimando 0 tamanho da população em aproximadamente 42000 indivíduos a partir de sobrevôos realizados em 1996. Há indícios de que esta população de toninhas possa estar em declínio (Secchi 1999, 2006, Kinas 2002, Lammardo 2002, Secchi et al. 2003a) e que a taxa de crescimento populacional não sustente os níveis atuais de capturas acidentais (Secchi 1999, 2006, Kinas 2002). 
Um aumento do esforço da pesca costeira de emalhe vem ocorrendo desde 1980 até os dias atuais (Reis et al. 1994, Haimovici 1997, Secchi et al. 1997, Boffo \& Reis 2003, Ferreira 2009), causando um maior impacto na zona costeira devido à sobreposição dessa atividade pesqueira com a distribuição da espécie, principalmente em águas entre o litoral e a isóbata de $30 \mathrm{~m}$. Kinas (2002) calculou uma taxa de incremento médio anual do esforço de pesca entre 1979 e 1994 de $72 \%$. Este aumento do esforço pode estar intensificando o impacto às toninhas que habitam a costa do Rio Grande do Sul. Embora existam trabalhos sobre capturas acidentais de toninhas (Secchi et al. 1997, 2006, Kinas \& Secchi 1998) e sobre encalhes (Pinedo \& Polacheck 1999) para a região de Rio Grande, existem poucos trabalhos sobre distribuição espaço-temporal das capturas acidentais, bem como sobre a relação entre as capturas acidentais e os encalhes de indivíduos (Secchi 1999, Dapper et al. 2005, Prado 2006).

Neste trabalho pretende-se descrever os padrões de distribuição espaço-temporal dos lances de pesca, das capturas acidentais e dos encalhes de toninhas, assim como identificar áreas e épocas de maior ocorrência das capturas acidentais.

\section{MATERIAL E MÉTODOS}

Os registros de capturas acidentais foram provenientes do monitoramento de uma porção da frota de emalhe costeiro sediada no Porto de Rio Grande

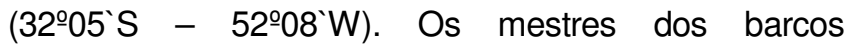
monitorados realizaram o preenchimento voluntário de cadernos de bordo com dados das capturas acidentais. As informações contidas nos cadernos incluíam: posição geográfica, tipo de rede utilizada, profundidade, data e local da pesca. Durante janeiro de 2002 e dezembro de 2003 monitorou-se o desembarque de 15 e 20 embarcações, respectivamente, (14 a 18\%) da frota de emalhe costeiro (112 embarcações). As informações obtidas neste período foram subdivididas em unidades menores (meses), quando necessário, para fins de comparação.

As embarcações monitoradas neste estudo utilizaram rede de emalhe de espera de fundo para capturar a pescada-olhuda (Cynoscion guatucupa) e a corvina (Micropogonias furnierı), e redes de cerco para a captura de anchova (Pomatomus saltatrix). Os barcos operaram principalmente entre o farol de Mostardas (3114'S) e a barra do Chuí (334'S) (Figura 1) em profundidades inferiores a $100 \mathrm{~m}$. Uma descrição mais detalhada da frota e da pescaria pode ser encontrada em Secchi et al. (1997), Boffo \& Reis (2003) e Ferreira (2009).

Para melhor expressar a distribuição temporal dos lances de pesca, foi definida a variável temporada de pesca, como um ciclo de pesca com início em 21 de dezembro e término em 20 de dezembro do ano seguinte subdivididas em quatro estações: verão de 21 de dezembro a 20 de março; outono de 21 de março a 20 de junho; inverno de 21 de junho a 20 de setembro; primavera de 21 de setembro a 20 de dezembro. No presente estudo foram analisadas apenas as temporadas de 2002 e 2003.

Os registros de encalhes foram obtidos através de monitoramentos sistemáticos, realizados entre junho de 2002 e dezembro de 2003, num trecho de aproximadamente $450 \mathrm{Km}$ de costa entre a barra do Chuí (33\%44'S) e a barra da Lagoa do Peixe (3121'S), com início nos molhes leste e oeste da barra de Rio Grande (320.5 S) para o percurso das áreas norte e sul, respectivamente. Os percursos foram realizados semanalmente em um veículo com tração nas quatro rodas, com um a quatro observadores por viagem, que registraram os mamíferos marinhos ao longo do percurso na área compreendida entre a linha d'água e a base das dunas, a uma velocidade média de $60 \mathrm{~km} / \mathrm{h}$. Quando uma carcaça era encontrada, sua posição foi determinada utilizando um GPS, assim como a distância em quilômetros desde o início do percurso. Sempre que possível, o animal foi sexado, medido e amostras biológicas foram coletadas e ingressadas à coleção do Laboratório de Tartarugas e Mamíferos Marinhos da Universidade Federal do Rio Grande (IOFURG). Para evitar a recontagem de um mesmo indivíduo em saídas subseqüentes, cada animal amostrado e contado era marcado com tinta spray.

A costa foi dividida em cinco áreas considerando pontos fixos de referência na faixa litorânea (i.e. faróis): 1 - entre molhes da barra do Chuí e farol Albardão (ChAl); 2 - farol Albardão e farol Sarita (AISa); 3 - farol Sarita e molhes da barra de Rio Grande (SaBa); 4 - molhes da barra de Rio Grande e farol Conceição (BaCo) e; 5 - farol Conceição e farol Mostardas (CoMo) (Figura 1). A 
profundidade foi dividida em sete categorias, definidas a registradas em profundidades acima de 35 metros foram cada 5 metros. Os lances de pesca e as capturas agrupados em apenas uma categoria.

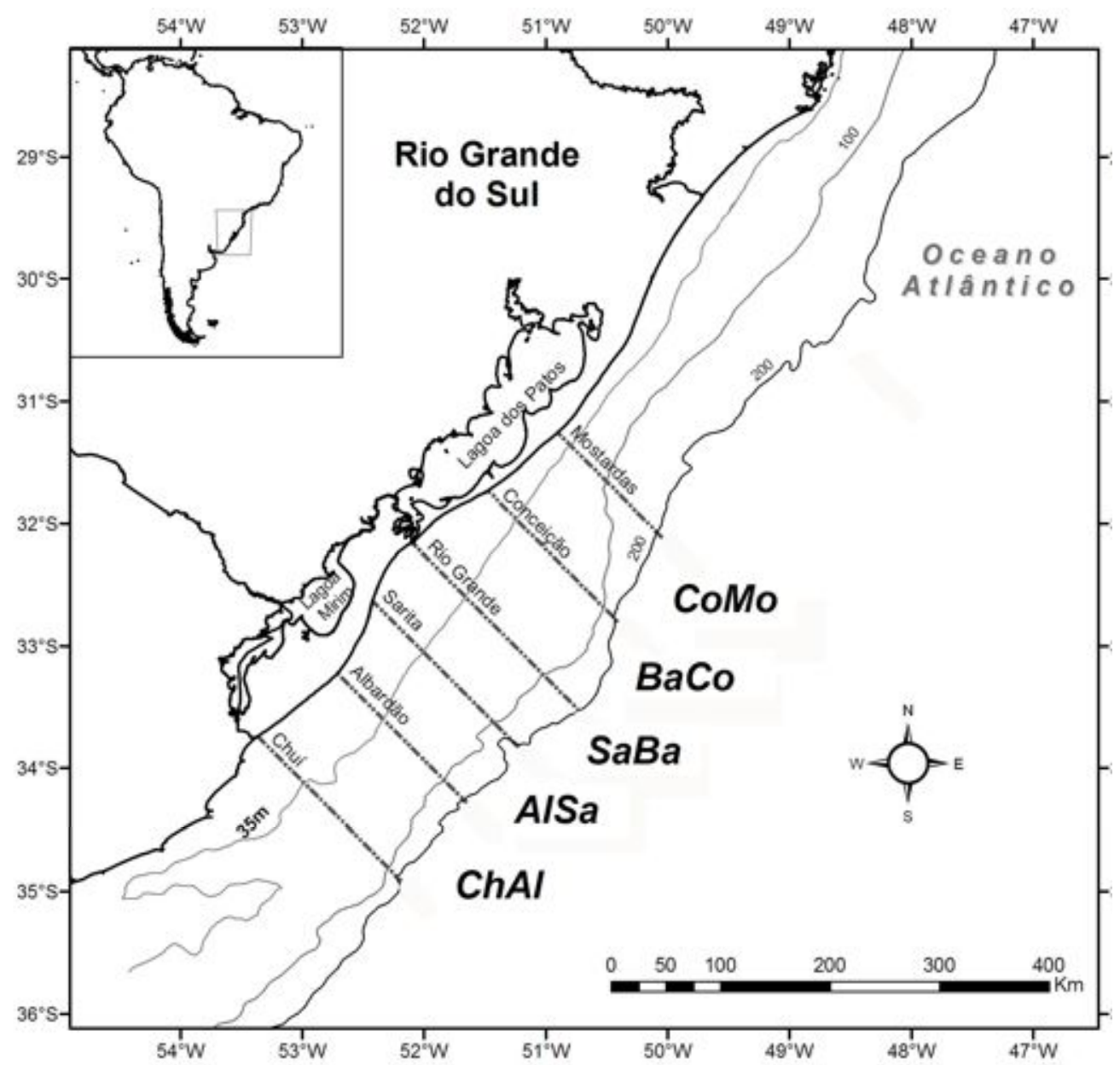

Figura 1 - Área de estudo e divisões das áreas ao longo da costa utilizadas no presente estudo. Chuí - Albardão (ChAl), Albardão - Sarita (AISA), Sarita - Barra (SaBa), Barra - Conceição (BaCo), Conceição - Mostardas (CoMo).

Para calcular as taxas de captura acidental de toninhas por unidade de esforço (CaPUE), utilizou-se o número de toninhas capturadas por 1.000 metros lineares de rede. Devido ao pequeno número amostral e a diferença na unidade de esforço, a CaPUE não foi calculada para rede de anchova. Ao serem calculadas as taxas de encalhe de toninhas, utilizou-se o número de toninhas encalhadas por unidade de esforço (EPUE), neste caso, expresso como número de toninhas encalhadas a cada $100 \mathrm{~km}$ de praia. Para verificar a existência de diferenças significativas na taxa de captura de toninhas entre os locais, as estações e os meses do ano foram utilizados o teste de Wilcoxon para duas amostras e Kruskal-Wallis para amostras múltiplas (Zar 1999). As análises estatísticas foram realizadas utilizando o software R versão 2.8.0 (2008).
As informações de lances de pesca, de capturas acidentais e de encalhes de toninhas foram inseridas em mapas georeferenciados de localização por estação do ano. Para descrever e comparar os padrões espaciais dos encalhes e das capturas acidentais, células de $20 \mathrm{~km}$ por $20 \mathrm{~km}$ foram definidas sobre a linha de costa na área de estudo e foi calculado o número de animais encalhados dentro de cada célula. Também foram criadas células de $20 \times 20 \mathrm{~km}$ para a região costeira e calculado o número de capturas acidentais e de lances de pesca dentro de cada célula.

Para caracterizar o vento predominante durante $o$ período de estudo, foi utilizada a média mensal climatológica da componente paralela a costa do stress do vento de uma reanálise global (NCEP www.cdc.noaa.gov/cdc/reanalysis/ reanalysis.shmtl) obtidos de pontos próximos à costa. O módulo do vento 
(valores positivos) e os valores de EPUE foram submetidos à análise de correlação linear de Spearman e os valores de significância foram ordenados segundo o teste "t", ao nível de $5 \%$ de probabilidade $(\alpha=0,05)$.

\section{RESULTADOS}

Lances de pesca e capturas acidentais

Foram analisados 690 lances de pesca de 23 embarcações diferentes, correspondendo a $20,5 \%$ da frota pesqueira de emalhe costeiro $(n=112)$. Destes lances 86,5\% não tiveram o registro de captura acidental de toninhas, enquanto que $13,5 \%$ dos lances capturaram 139 toninhas (Tabela 1). O maior esforço de pesca ocorreu em profundidades de 16 a $25 \mathrm{~m}$ $(\mathrm{KW}=47,588 ; \mathrm{gl}=6 ; \mathrm{p}<0,001)$. A captura acidental envolvendo um exemplar por lance de pesca predominou, ocorrendo em $46,3 \%$ dos casos. Capturas envolvendo dois e três exemplares por lance representaram $30,9 \%$ e $13,2 \%$ dos registros, respectivamente. $\mathrm{O}$ número máximo de toninhas capturadas em um único lance foi de cinco exemplares.

Tabela 1 - Informações referentes ao esforço de pesca (№ de lances, № de barcos monitorados, comprimento da rede $(m)$ ), esforço de monitoramento de praia (№ de saídas de praia, km percorrido), capturas acidentais e encalhes nos períodos estudados (2002 e 2003)

\begin{tabular}{|c|c|c|c|c|c|c|c|}
\hline Ano & № de lances & $\begin{array}{c}\text { №Barcos } \\
\text { monitorados }\end{array}$ & $\begin{array}{c}\text { Comprimento } \\
\text { (média } \pm d p \text { ) da rede }(\mathrm{m})\end{array}$ & $\begin{array}{l}\text { Capturas } \\
\text { Acidentais }\end{array}$ & $\begin{array}{c}\text { № saídas de } \\
\text { praia }\end{array}$ & $\begin{array}{c}\text { km } \\
\text { percorrido }\end{array}$ & Encalhes \\
\hline 2002 & 289 & 15 & $9158,07( \pm 2190,50)$ & 64 & 17 & 2929,9 & 160 \\
\hline 2003 & 401 & 20 & $10878,46( \pm 2482,90)$ & 75 & 35 & 4799,3 & 188 \\
\hline Total geral & 690 & 23 & 10157.90 & 139 & 52 & 7729,2 & 348 \\
\hline
\end{tabular}

A maioria das capturas acidentais (93,4\%) efetuadas pelas embarcações monitoradas ocorreu em profundidades inferiores a $35 \mathrm{~m}$, sendo que $77,2 \%$ das capturas ocorreram entre as profundidades de 11-25m. As taxas de CaPUE apresentaram valores maiores para a classe 05-10m (Figura 2).

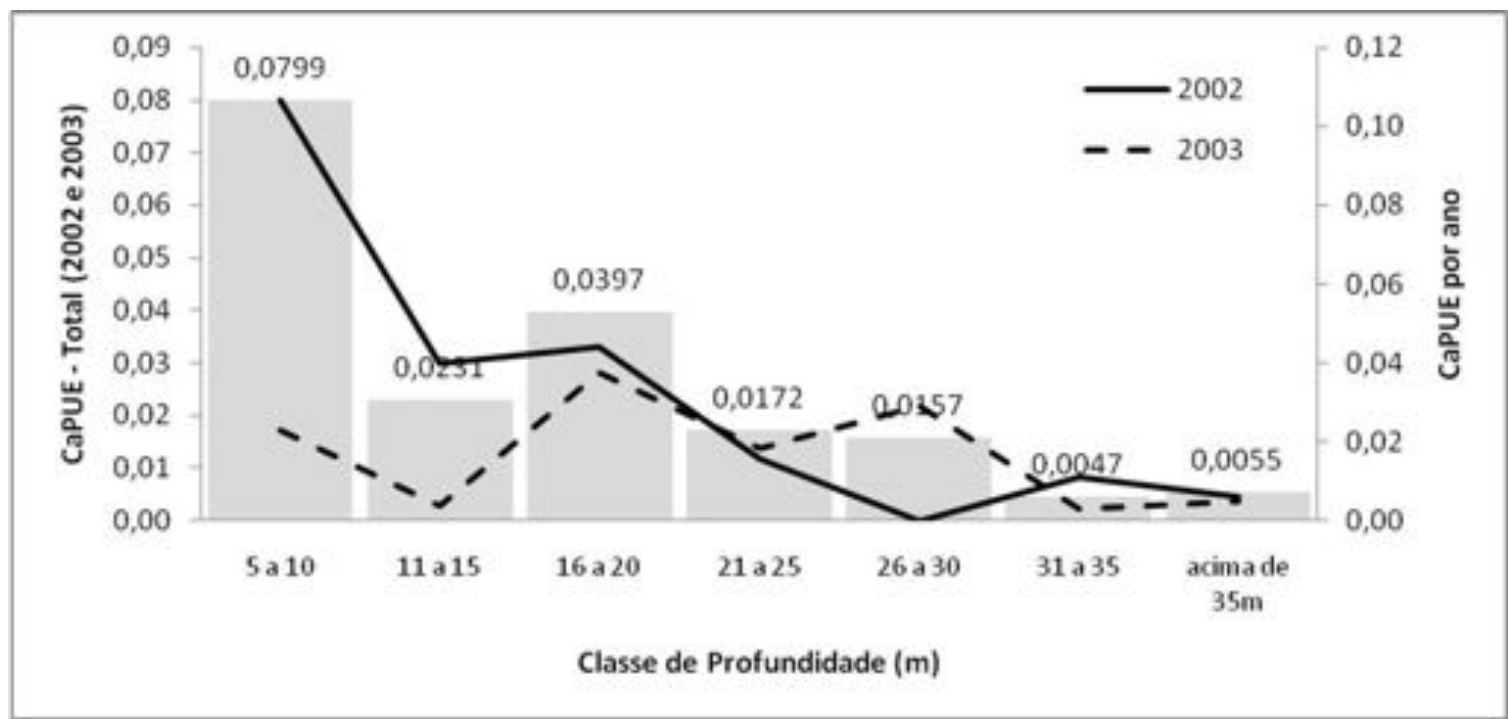

Figura 2 - Distribuição da CaPUE (№ de toninhas/1000m de rede) por classe de profundidade para todo o período estudado (barras verticais) e por temporada de pesca (linha contínua 2002, linha tracejada 2003). Eixo da esquerda representa a CaPUE total para todo o período estudado e o eixo da direita referente a cada ano estudado.

A distribuição espacial das taxas de CaPUE, em relação à barra de Rio Grande, demonstra que não houve predominância nas taxas ao norte ou ao sul da BRG $(W=59676,5 ; \quad g l=1 ; \quad p=0,08)$, que apresentaram taxas de 0,0190 e 0,0198 toninhas por $1000 \mathrm{~m}$ de rede, respectivamente. No entanto, quando separados em sub-áreas de amostragem, o local com maior taxa de capturas foi a área ChAl, compreendida 
entre a barra do Chuí e o farol Albardão (KW=13,958; $\mathrm{gl}=5 ; \mathrm{p}=0,01)$, apresentando 0,0347 CaPUE. Quando as temporadas de pesca são observadas separadamente, em 2002 houve uma predominância das capturas acidentais para a área ao norte da barra de Rio Grande, enquanto em 2003 o maior número observado correspondeu à área ao sul da barra de Rio Grande (Figura 3).

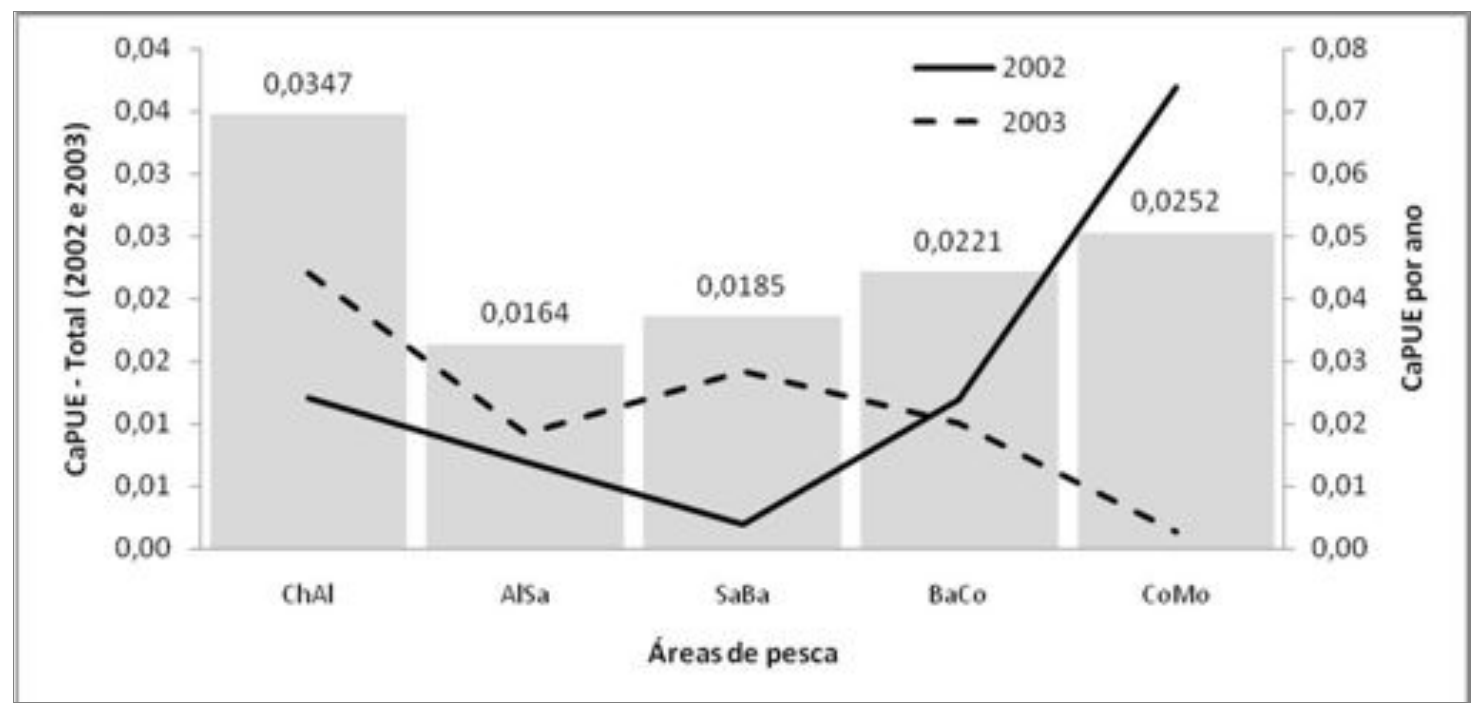

Figura 3 - Distribuição da CaPUE (№ de toninhas/1000m de rede) por local de pesca para todo o período estudado (barras verticais) e por temporada de pesca (linha contínua 2002, linha tracejada 2003). Eixo da esquerda representa a CaPUE total para todo o período estudado e o eixo da direita referente a cada ano estudado.

A CaPUE foi calculada para as redes passivas (corvina e pescada) não apresentando diferenças significativas entre as redes $(\mathrm{W}=52549 ; \mathrm{gl}=1$; $\mathrm{p}=0,721)$. Os dois anos estudados apresentaram uma relação inversa. A CaPUE da rede de corvina aumentou de 2002 para 2003 enquanto a CaPUE da rede de pescada diminuiu.
A CaPUE não apresentou uma diferença sazonal na proporção das capturas acidentais $(\mathrm{KW}=6,011 ; \mathrm{gl}=3 ; \mathrm{p}=0,11)$. Contudo, a primavera apresentou a maior CaPUE seguida do inverno, do outono e do verão (Figura 4). Os meses de julho e outubro apresentaram a maior CaPUE (Figura 5), mas não houve diferenças significativas entre os mesmos $(K W=20,634 ; g l=11 ; p<0,05)$.

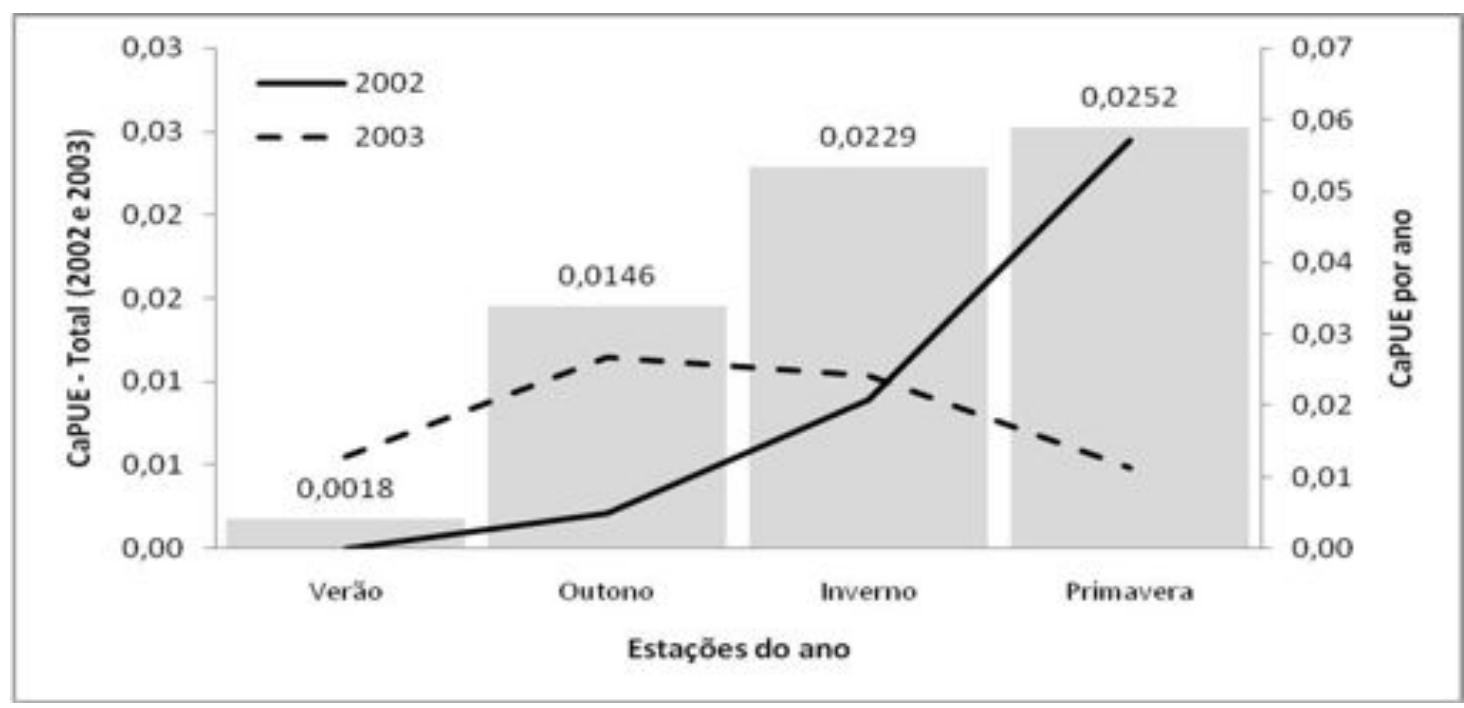

Figura 4 - Distribuição da CaPUE (№ de toninhas/1000m de rede) por estações do ano para todo o período estudado (barras verticais) e por temporada de pesca (linha contínua 2002, linha tracejada 2003). Eixo da esquerda representa a CaPUE total para todo o período estudado e o eixo da direita referente a cada ano estudado. 


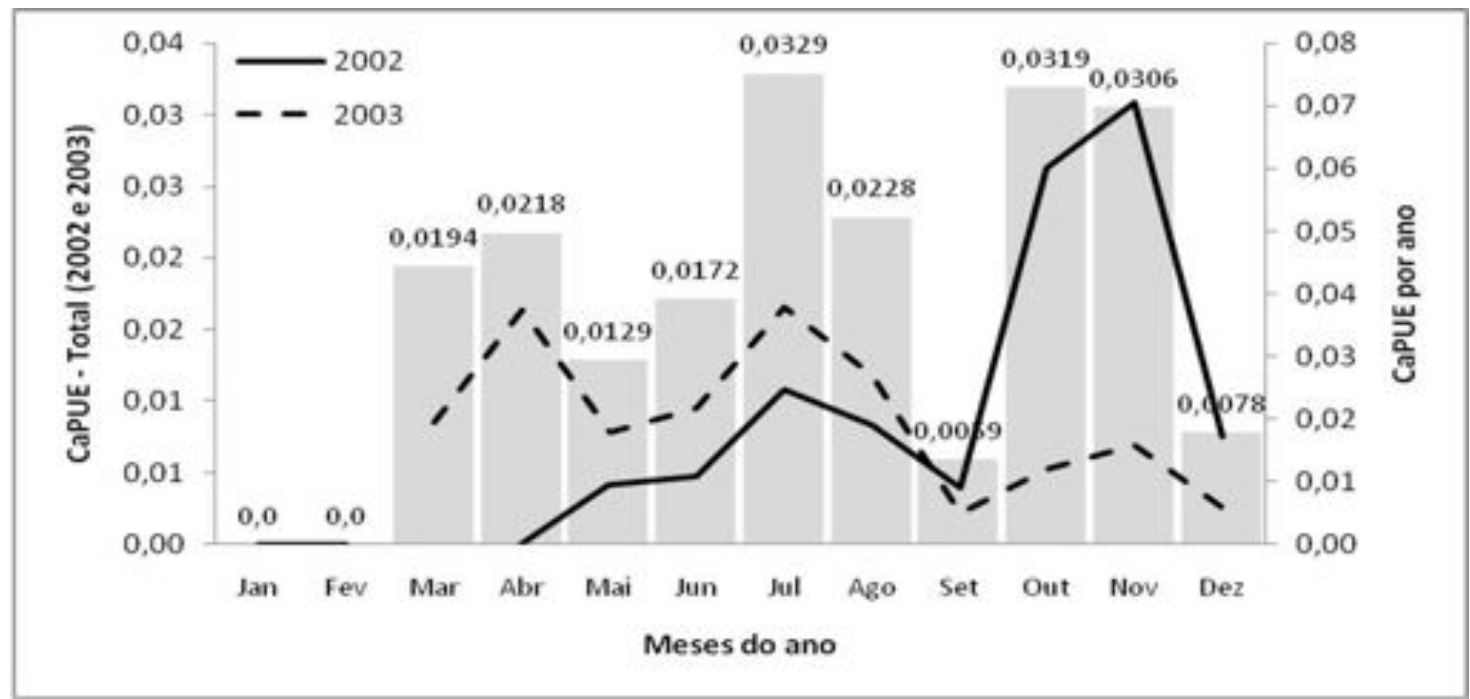

Figura 5 - Distribuição da CaPUE (№ de toninhas/1000m de rede) por meses do ano para todo o período estudado (barras verticais) e por temporada de pesca (linha contínua 2002, linha tracejada 2003). Eixo da esquerda representa a CaPUE total para todo o período estudado e o eixo da direita referente a cada ano estudado.

\section{Encalhes}

Durante o período de julho de 2002 a dezembro de 2003 foram realizados 52 monitoramentos de praia, dos quais 22 foram no sentido: barra de Rio Grande - Lagoa do Peixe (42\%), e 30 no sentido barra de Rio Grande - Chuí (58\%). Foram percorridos $7.779,2 \mathrm{~km}$ de praia $(148,63 \pm$ $59,38 \mathrm{~km}$ por saída). A maioria dos monitoramentos $(86,5 \%)$ percorreu mais de $100 \mathrm{~km}$. Houve o registro de pelo menos uma toninha em 28 percursos de praia
(53,8\%), e o máximo registrado em uma única saída foi de 119 toninhas. Foram utilizadas informações dos registros de 348 toninhas encalhadas nos monitoramentos de praia para o período estudado.

A distribuição espacial das taxas de encalhe por unidade de esforço (EPUE) mostra que não houve predominância de encalhes nas diferentes áreas ao longo da costa ( $K W=4,378 ; g l=4 ; p=0,83)$. Os maiores valores de EPUE para todo o período de estudo foram para as regiões do SaBa e AlSa (Figura 6).

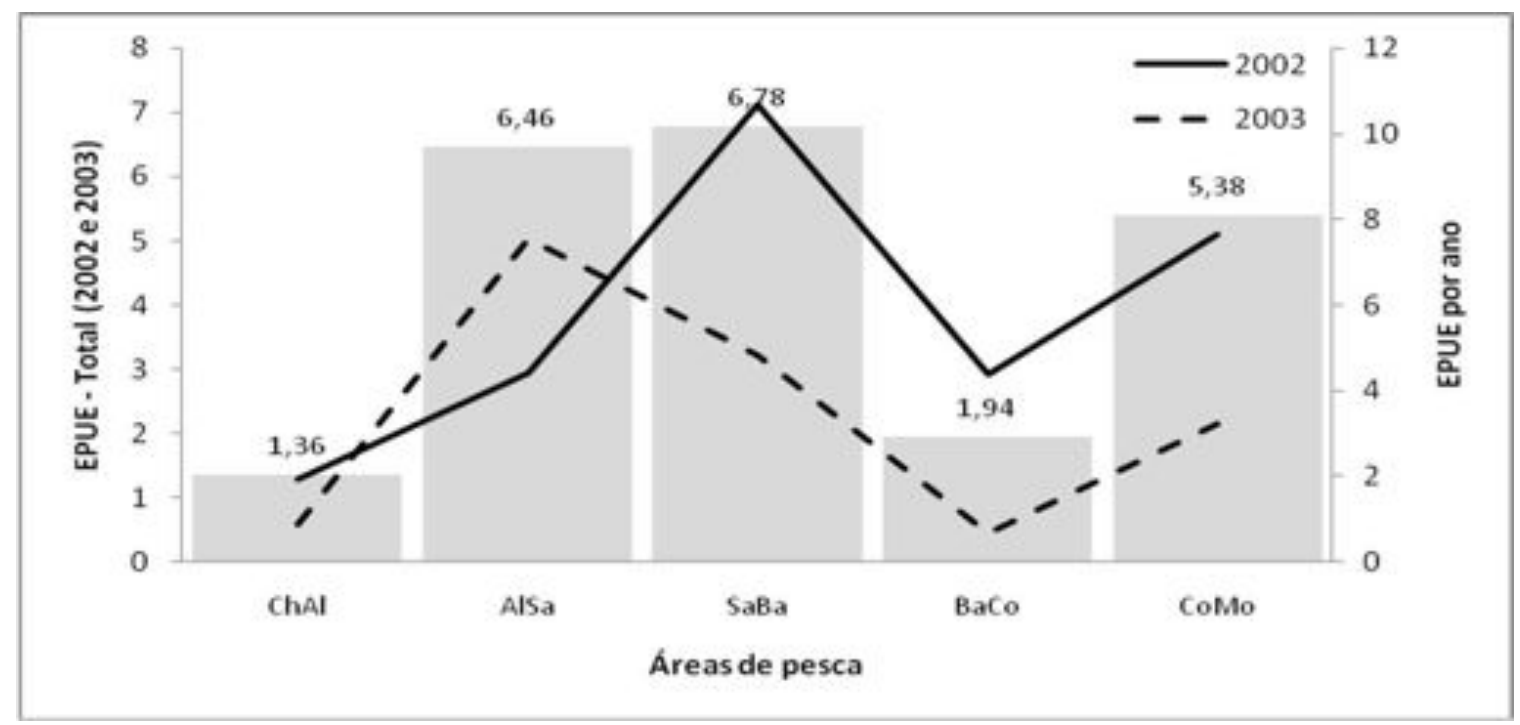

Figura 6 - Distribuição das EPUE (№ de toninhas $/ 100 \mathrm{~km}$ ) por local de pesca para todo o período estudado (barras verticais) e por temporada de pesca (linha contínua 2002, linha tracejada 2003). Eixo da esquerda representa a EPUE total para todo o período estudado e o eixo da direita referente a cada ano estudado. 
Houve uma diferença sazonal na proporção dos encalhes ( $K W=8,045 ; g l=3 ; p<0,05)$. A EPUE apresentou valores maiores durante o outono $\mathrm{e}$ primavera (Figura 7), e novembro, dezembro e maio (Figura 8).

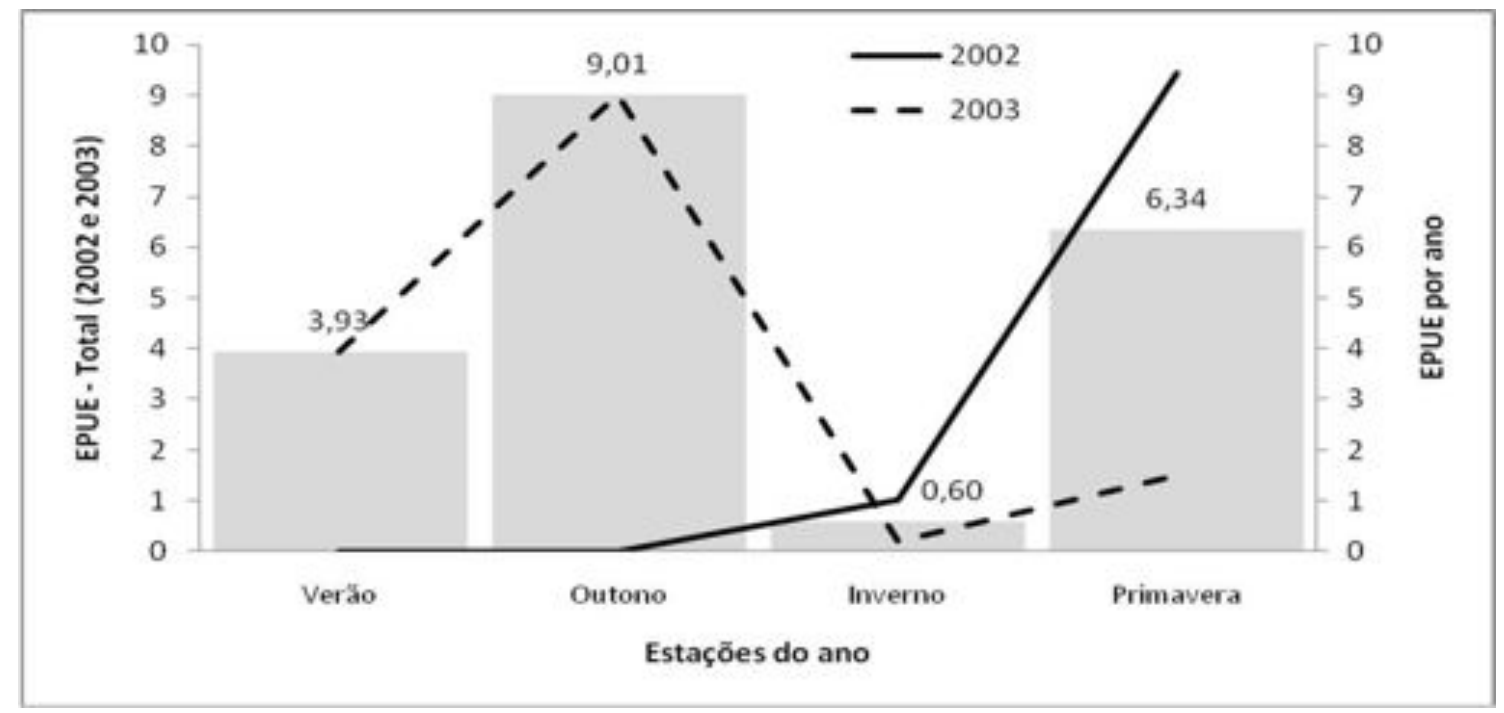

Figura 7 - Distribuição das EPUE (№ de toninhas/100km) por estações do ano para todo o período estudado (barras verticais) e por temporada de pesca (linha contínua 2002, linha tracejada 2003). Eixo da esquerda representa a EPUE total para todo o período estudado e o eixo da direita referente a cada ano estudado.

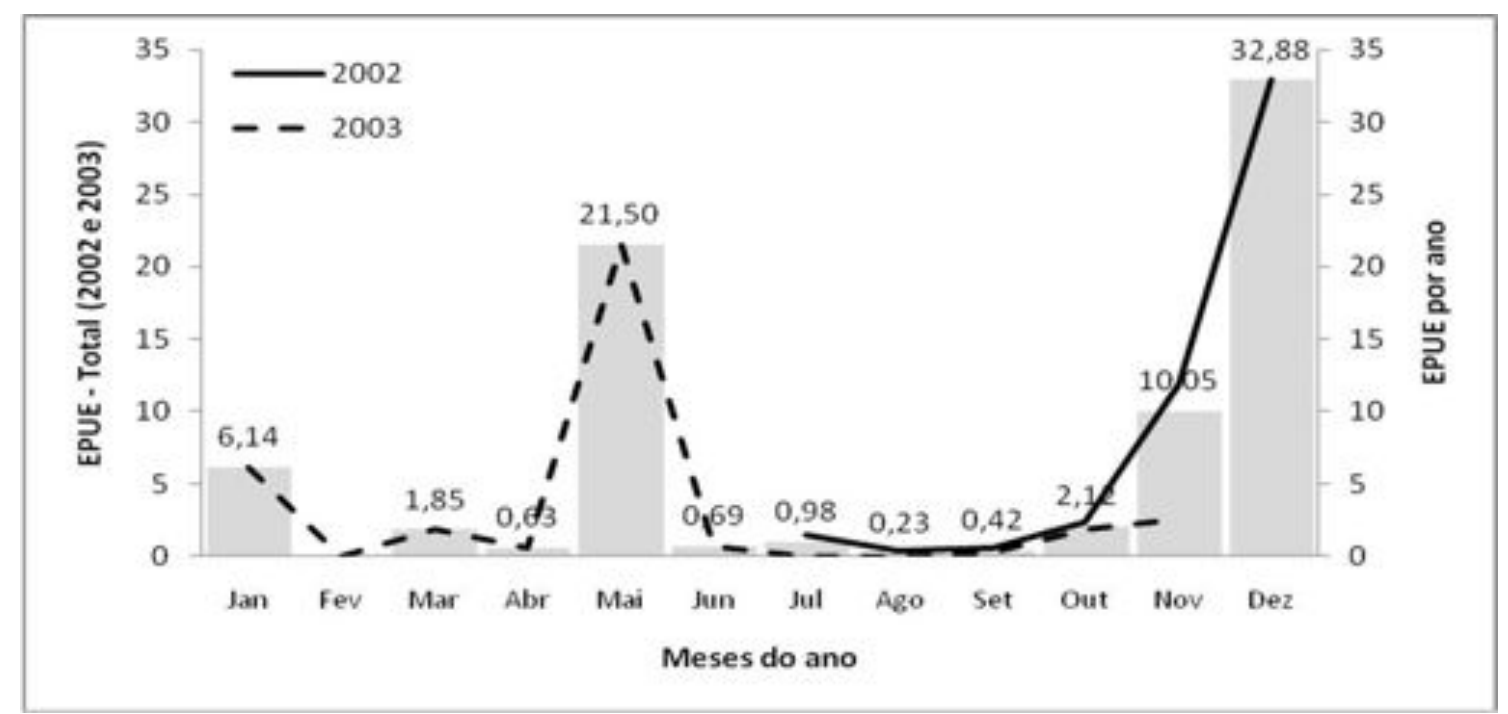

Figura 8 - Distribuição das EPUE (№ de toninhas/100km) por meses do ano para todo o período estudado (barras verticais) e por temporada de pesca (linha contínua 2002, linha tracejada 2003). Eixo da esquerda representa a EPUE total para todo o período estudado e o eixo da direita referente a cada ano estudado.

Distribuição espacial dos lances de pesca e capturas acidentais

Durante o ano de 2002 não foi constatada uma preferência por local de pesca ao longo do ano. Os lances estiveram distribuídos ao sobre toda a plataforma, até profundidades de $100 \mathrm{~m}$, com exceção da primavera quando os lances ficaram restritos a regiões mais próximas a costa. As capturas acidentais de toninhas foram realizadas em áreas próximas à costa e aos faróis Albardão e Conceição, sem registros de capturas durante o verão (Figura 9). Em 2003, os lances de pesca ficaram concentrados em profundidades inferiores a $30 \mathrm{~m}$. No verão e 
outono os lances de pesca ficaram concentrados em áreas ao sul da barra de Rio Grande, enquanto no inverno e primavera os lances de pesca estavam distribuídos ao longo de toda costa. As capturas de toninhas ocorreram 0 ano inteiro e a maior concentração de capturas ficou na área em frente ao farol Sarita, com registro de capturas em profundidades superiores a $30 \mathrm{~m}$ na estação da primavera (Figura 10).
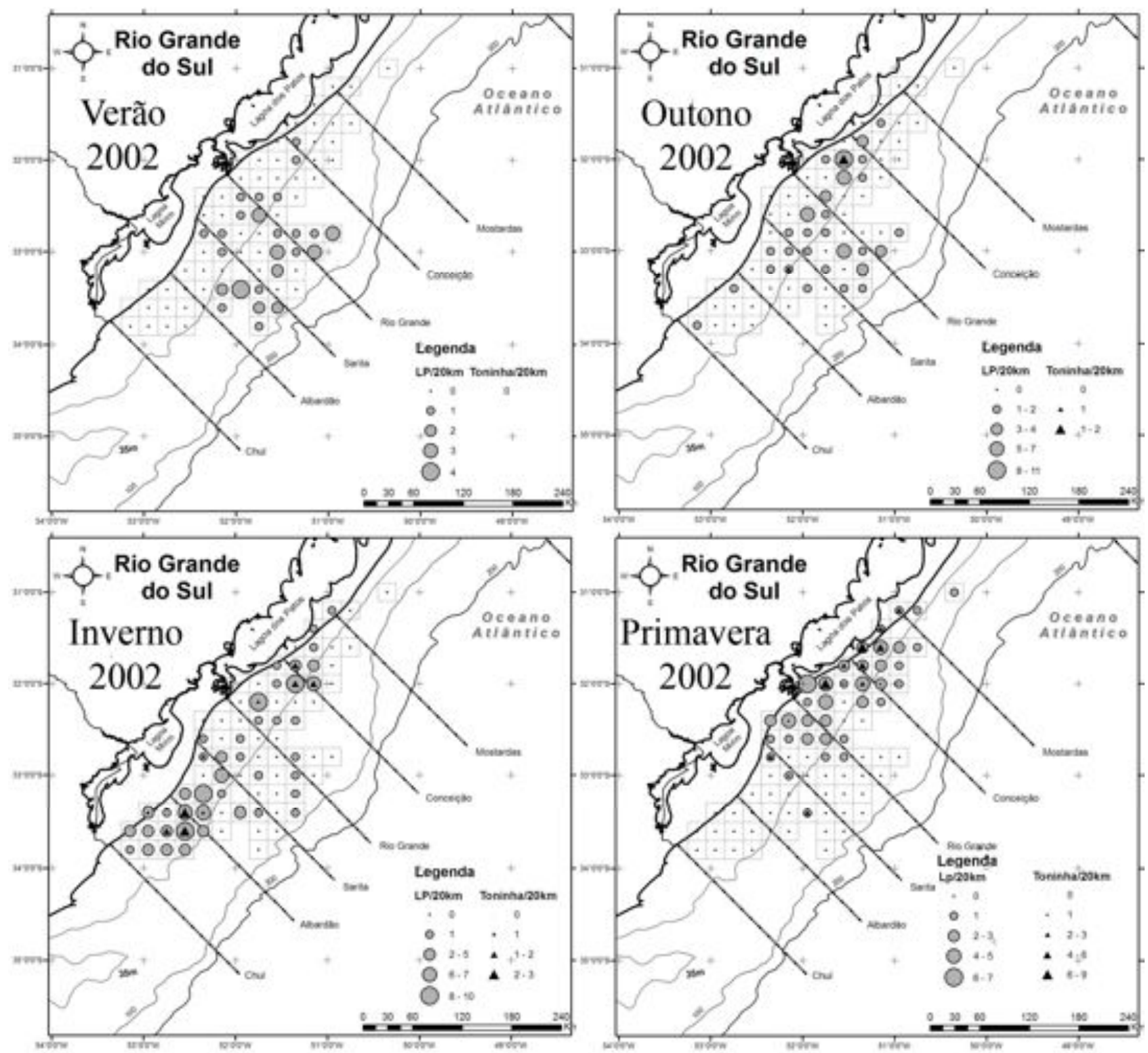

Figura 9 - Mapas de distribuição das capturas acidentais de toninhas (Pontoporia blainvillel) nas quatro estações do ano em relação à distribuição geográfica dos lances de pesca (LP) na área de estudo para o ano de 2002. 

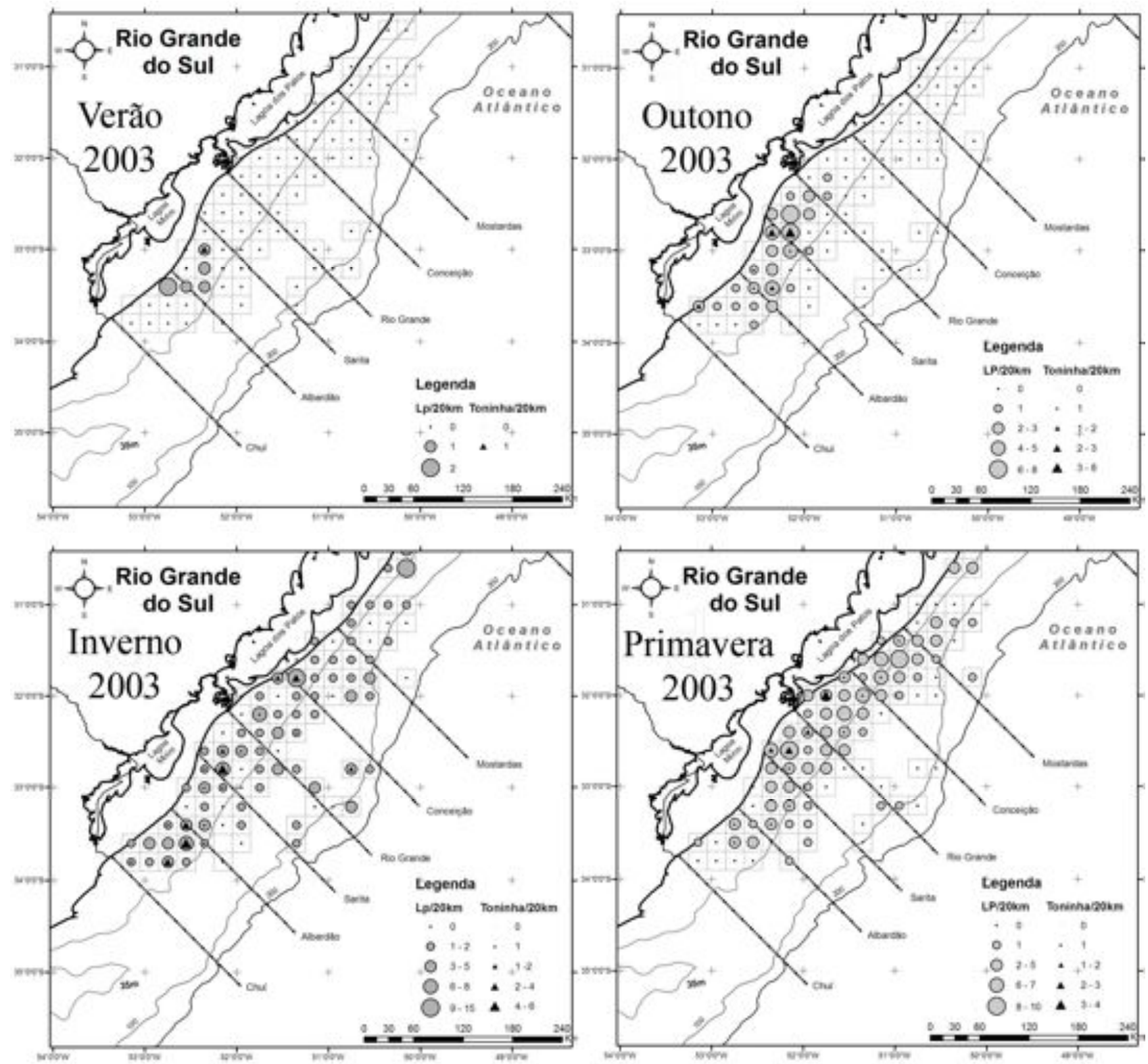

Figura 10 - Mapas de distribuição das capturas acidentais de toninhas (Pontoporia blainvilleı) nas quatro estações do ano em relação à distribuição geográfica dos lances de pesca (LP) na área de estudo para o ano de 2003.

Distribuição espacial dos encalhes

No período de inverno e primavera de 2002 os encalhes estavam em áreas adjacentes as capturas acidentais que estão localizadas em áreas próximas aos faróis Albardão e Conceição (Figura 11). Durante o ano de 2003 os encalhes ocorreram em áreas adjacentes às capturas acidentais, e principalmente aos lances de pesca. A maior concentração de encalhes ocorreu em áreas próximas aos faróis Albardão, Sarita e Conceição (Figura 11). 

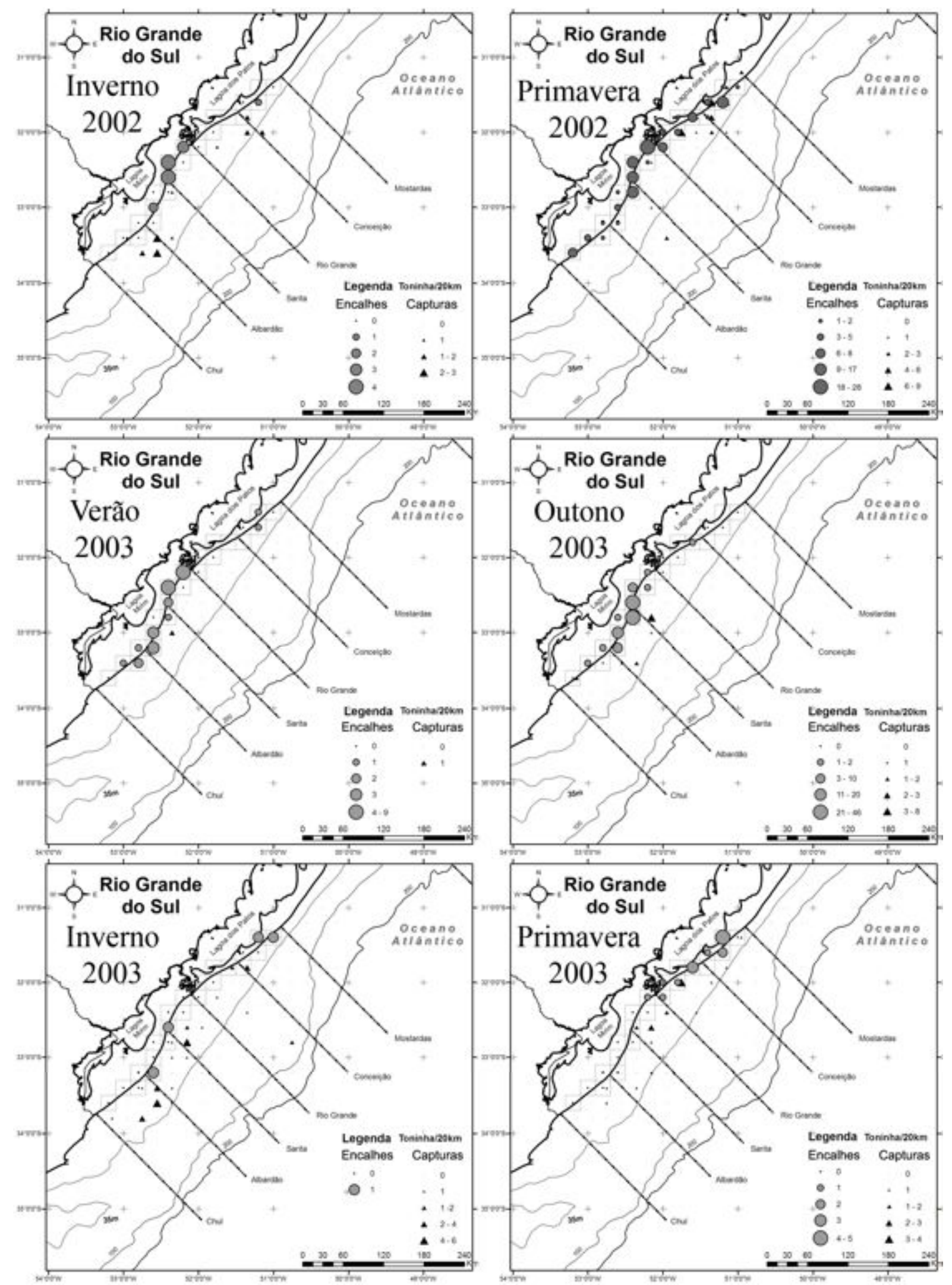

Figura 11 - Mapas de distribuição dos encalhes de toninhas (Pontoporia blainvilleı) nas quatro estações do ano em relação à distribuição geográfica das capturas acidentais de toninhas na área de estudo.

Ventos do quadrante norte prevaleceram durante boa parte da primavera e verão (Out Jan), no período de estudo. Nas estações de outono e inverno, ventos do quadrante sul foram mais intensos. Foi observada uma correlação forte entre a taxa de encalhe e módulo do índice do vento (Figura 12, $r_{s}, r=-0,73 ; p<0,05$ ). O pico 
de EPUE em maio de 2003 coincidiu com a máxima intensidade de vento sul durante o período estudado (Figura 13a). Também se observou um maior esforço, em número de lances, no ano de 2003, e uma diminuição no CaPUE (Figura13b).

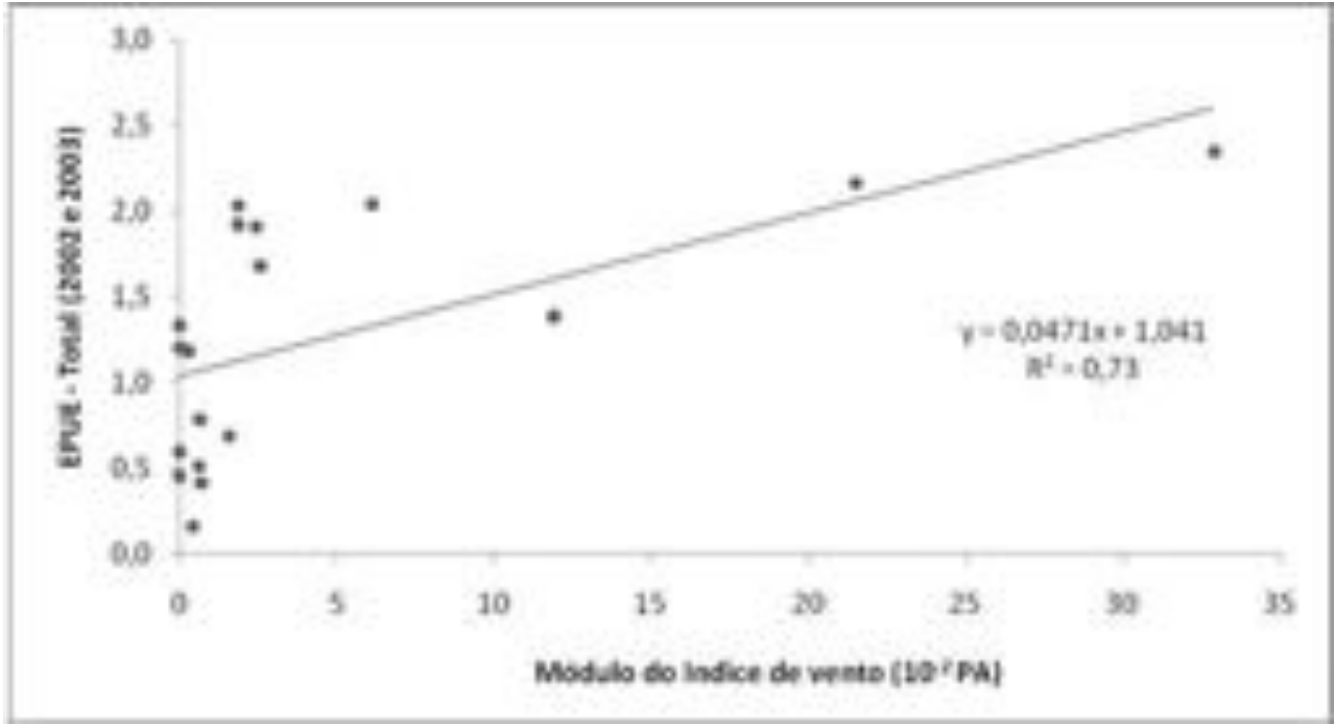

Figura 12 - Relação entre encalhe por unidade de esforço (EPUE=№ de toninhas/100km) por módulo de índice de vento.
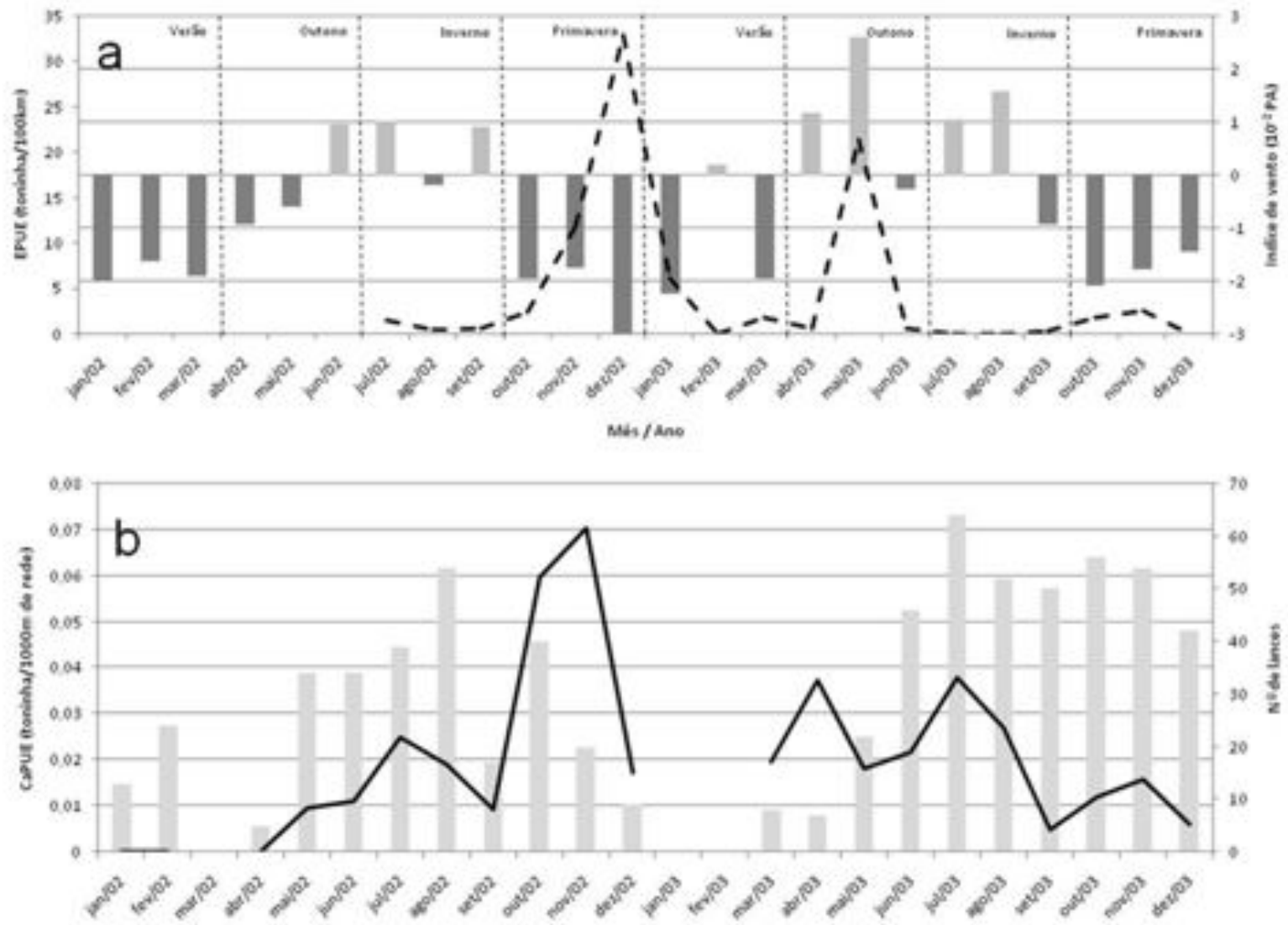

Figura 13 - a) Eixo da esquerda: EPUE mensal ao longo do período estudado (Jul/02-Dec/03), linha tracejada. Eixo da direita: Barras com intensidade do vento, valores positivos se referem a ventos do quadrante sul, valores negativos do quadrante norte.

b) Eixo da esquerda: CaPUE mensal ao longo do período estudado, linha contínua. Eixo da direita: Barras com número de lances. 


\section{DISCUSSÃO}

As pescarias não apresentaram fidelidade a uma área específica durante o período de estudo, havendo também a sobreposição de pescarias de corvina e de pescada durante os meses de agosto a outubro. Durante a primavera, as capturas acidentais observadas ocorreram junto com a maioria dos lances de corvina ao longo da costa e em profundidades abaixo dos $30 \mathrm{~m}$. Neste período foram registrados os maiores picos de encalhes.

$\mathrm{Na}$ primavera também se registraram valores altos de CaPUE e EPUE, sugerindo uma sobreposição dos locais de pesca com áreas de concentração da espécie na costa em regiões de baixa profundidade. Este fato pode potencializar um efeito negativo sobre a espécie, considerando que este período corresponde ao pico de nascimentos de toninhas no Rio Grande do Sul (Danilewicz et al. 2000, Danilewicz 2003).

Apesar de terem ocorrido mudanças nas áreas preferenciais de pesca nos dois anos estudados, os resultados obtidos sugerem uma relação entre as áreas de pesca e de encalhes de toninhas. Variações nos valores de CaPUE podem ser explicadas de diversas maneiras e podem estar associadas a variações no esforço pesqueiro, dinâmica da frota pesqueira, diminuição na abundância de espéciesalvo e mudanças climáticas (Evans et al. 2005, Walker et al. 2005, Leeney et al. 2008).

Embora as duas áreas de maior concentração de capturas acidentais estejam entre os faróis Albardão e Sarita e entre o farol Conceição e barra de Rio Grande, as taxa de encalhes não apresentaram diferenças ao longo das áreas, apresentando os maiores valores nas áreas ao sul da barra de Rio Grande. Ao longo do período de estudo foram registrados encalhes e capturas acidentais de toninhas ao longo de toda a costa. Este fato sugere que a espécie permaneça na área do Rio Grande do Sul ao longo de todo o ano, conforme sugerido em estudos anteriores (e.g. Secchi et al. 1997; Pinedo \& Polacheck 1999). Durante o ano de 2003 foi registrado um grande número de toninhas encalhadas em um único monitoramento de praia no mês de maio. Este acontecimento é raro e pode indicar a existência de outras artes de pesca atuando na área, uma situação de difícil controle e que pode representar uma fonte adicional de mortalidade. Excluindo este evento raro de 2003, os padrões de encalhes aqui registrados foram semelhantes aos de Pinedo \& Polacheck (1999), encontrando as maiores taxas de encalhe de setembro a dezembro e as menores para os meses de janeiro a agosto.

Ainda que animais encalhados não representem completamente os animais capturados nas artes de pesca, estes encalhes podem ser considerados bons indicadores de capturas acidentais se associados a estudos de marcação e recaptura de animais capturados mortos em redes de pesca (e.g. Prado 2006). As maiores taxas de encalhes, registradas ao norte das áreas com altas taxas de capturas acidentais, principalmente durante o inverno, podem ser explicadas pela circulação na plataforma interna. A circulação é afetada por descargas de água doce e variações sazonais do vento, predominantemente para nordeste durante o outono e inverno (Palma et al. 2008), que pode transportar uma toninha morta para uma área mais ao norte do local onde ela foi capturada.

O maior número de exemplares de toninhas capturados acidentalmente na região perto da barra de Rio Grande e ao sul da mesma pode ser reflexo de um maior esforço de pesca dedicado nesta área durante o inverno e a primavera. Neste período, as características (nutrientes, temperatura, salinidade) das águas provenientes do Sistema Lagunar PatosMirim e do Rio da Prata, associadas aos regimes de ventos que variam de NE a SO, podem deixar a região mais produtiva (Seeliger et al. 1997, Soares \& Möller 2001). Este cenário oceanográfico, por sua vez, torna o ambiente mais favorável para a pesca e para a ocorrência de toninhas, e pode justificar o maior esforço da frota de pesca empregado nessa área e poderia explicar a maior concentração dos exemplares registrados neste estudo. Períodos de forte intensidade de ventos do quadrante sul causam transporte de água para o norte e em direção à costa, por efeito do transporte de Ekmam (Piola et al. 2005, 2008). Neste estudo foi encontrada uma relação positiva entre a taxa de animais encalhados com a intensidade, e sugere que o vento pode transportar carcaças de toninhas para a costa. Porém, foi analisada apenas a média mensal do vento, o que pode mascarar eventos como a passagem de sistemas frontais. Uma análise mais refinada dos 
dados (diária ou semanal) poderia mostrar uma melhor relação entre encalhes e eventos climáticos ou oceanográficos. Desta forma, os valores obtidos a partir de monitoramentos de praia devem ser vistos com cautela. Valores altos de encalhes também podem estar associados a fatores como mortalidade natural, ataque por tubarões, correntes marítimas e a passagem de sistemas frontais (Duguy 1978). Fatores como o afundamento de animais após avançado estado de decomposição ou o ataque por isópodes decompositores, impedem que indivíduos capturados e jogados de volta ao mar cheguem até a praia (Secchi et al. 1997, Secchi 1999), subestimando assim o número de animais na costa.

Os mapas aqui construídos representam uma primeira etapa de visualização espaço-temporal das áreas de maior risco de capturas de toninhas na costa sul do Rio Grande do Sul. Esta informação pode ajudar a gerenciar medidas de manejo e conservação da espécie. Com o aumento da exploração dos recursos pesqueiros no litoral e das atividades ligadas a este tipo de exploração, faz-se necessário o desenvolvimento de ferramentas eficientes de diagnóstico rápido que auxiliem a tomada de decisões de conservação e manejo. No caso específico da toninha, a confecção de mapas geo-referenciados da distribuição espaço-temporal das capturas, associados a informações sobre a dinâmica do ambiente marinho, permitem a obtenção de cenários mais objetivos. Os mapas não são o único meio de detecção de padrões espaciais, mas fornecem um sistema para a aquisição, análise e interpretação de dados biológicos, oceanográficos e ambientais georeferenciados. Este conjunto de dados pode ser usado para avaliar tendências de mudanças nas características do ambiente, mudanças temporais, padrões de distribuição espaço-temporal e densidades relativas, servindo como indicadores de viabilidade do ecossistema a curto, médio e longo prazo (Stanbury \& Starr 1999).

Em determinados pontos ao norte do litoral do Rio Grande do Sul há uma maior inclinação na plataforma continental, deixando-a mais estreita e fazendo com que a isóbata de $30 \mathrm{~m}$ esteja a menos que $20 \mathrm{~km}$ da costa. Na região mais ao sul esta inclinação é menor, deixando a distância entre a isóbata de $30 \mathrm{~m}$ e a costa relativamente maior, podendo chegar a mais de $50 \mathrm{~km}$. Aliado a esta topografia da costa, o tamanho das redes de pesca registradas no presente estudo é algo preocupante, visto que foram registradas redes de até $12 \mathrm{~km}$ de comprimento com $6 \mathrm{~m}$ de altura. Esta configuração corresponde a uma área de $72.000 \mathrm{~m}^{2}$ de rede, o que acaba por formar uma barreira intransponível para várias espécies em determinados pontos da costa, incluindo a toninha. Este fato é corroborado por valores mais altos de CaPUE no litoral norte do que no sul (Secchi \& Ott 2000). Isso é preocupante, dada a tendência de arrasteiros da pesca industrial utilizar em redes de emalhe aliado ao aumento expressivo do comprimento das redes na pesca costeira (Reis et al. 1994; Boffo \& Reis 2003; Secchi et al. 2004).

O estoque de toninhas da costa do Rio Grande do Sul e Uruguai enfrenta níveis altos de captura há algum tempo (Secchi et al. 2002, Secchi et al, 2003b) e, segundo estimativas, centenas de toninhas, têm sido capturadas anualmente pela pesca de emalhe (Secchi 1999, Secchi et al. 2003b, 2006). As taxas de remoção de indivíduos do estoque estimadas recentemente sugerem um sério comprometimento da população em questão (Secchi 2006). Desta forma, existe a necessidade urgente de uma regulamentação no esforço de pesca e talvez o estabelecimento de áreas ou períodos de exclusão à pesca. Medidas possivelmente eficazes para a conservação desta espécie seria a diminuição do tamanho e tempo de uso de redes de emalhe, bem como a criação de uma área de proteção ambiental, com exclusão de pesca em parte da costa do Rio Grande do Sul, em águas rasas até a isóbata dos $30 \mathrm{~m}$, preferencialmente abrangendo a área entre os faróis Conceição, Albardão e Sarita. Este estudo destaca a importância de coleta de dados ecológicos em longo prazo e a importância da integrar estes com séries de dados oceanográficos e climáticos similares para identificar testes padrões do ecossistema.

\section{AGRADECIMENTOS}

A todos que contribuíram para a realização deste trabalho. Aos pescadores da barra de Rio Grande, à Lília Fidélix, à equipe do Museu Oceanográfico "Prof. Eliezer de C. Rios" e ao Fernando Hirata. Este trabalho foi realizado sob licença do IBAMA no 035/2003/RS, com o apoio financeiro de algumas instituições conservacionistas incluindo a YAQU PACHA, CAPES, FAPERGS e CNPq. 


\section{REFERÊNCIAS}

BERTOZZI, CP \& AN ZERBINI. 2002. Incidental mortality of toninha (Pontoporia blainvillel) in the artisanal fishery of Praia Grande, São Paulo state, Brazil. The Lat. Am. J. Aquatic Mamm. (special issue) 1: 153-160.

BOFFO, MS \& EG REIS. 2003. Atividade pesqueira da frota de média escala no extremo sul do brasil. Atlântica, 25(2), 171-178.

CORCUERA, J, F MONZON, EA CRESPO, A AGUILAR, \& JA RAGA. 1994. Interactions between marine mammals and the coastal fisheries of necochea and claromecó (Buenos Aires Province, Argentina). Reports of the International Whaling Commission, Cambridge, 15(283-290).

CRESPO, E.A., HARRIS G. e GONZALÉZ R. 1998. Group size and distributional range of the franciscan, Pontoporia blainvillei. Mar. Mamm. Sci. 14: 845-849.

DANILEWICZ, D. 2003. Reproduction of female franciscana (Pontoporia blainvillel) in Rio Grande do Sul, southern Brazil. The Lat. Am. J. Aquatic Mamm. LAJAM, 2 (2): 67-78.

DANILEWICZ, D, ER SECCHI, PH OTT, \& IB MORENO. 2000. Analyses of the age at sexual maturity and reproductive rates of franciscanas (Pontoporia blainvillei) from Rio Grande do Sul, Southern Brazil. Comum. Mus. Ciênc. Tecnol. PUCRS 13(1):89-98. DAPPER, C, ER SECCHI, PG KINAS \& M MUELBERT. 2005. Seasonal, spatial and gear type vulnerability of franciscana dolphin in southern Brazil. Document SC/57/SM7 presented to the Scientific Committee of the International Whaling Commission, Ulsan, South Korea, May/June 2005.

DI BENEDITTO, A.P.M., RAMOS, R.M.A. 2001. Biología e conservação de pequenos cetáceos no Norte do Estado do Rio de Janeiro. Fundação Estadual Norte Fluminense. 92p.

DUGUY, R. 1978. Researches on the mortality factors of cetaceans on the coasts of France. Aquat. Mamm. 6(1):9-13

EVANS K, R THRESHER, RM WARNEKE, CJA BRADSHAW, M POOK, D THIELE \& MA HINDELL. 2005. Periodic variability in cetacean strandings: links to large-scale climate events. Biol Lett. June 22; 1(2): 147-150.

FERREIRA, EC. 2009. A Dinâmica da Pesca Costeira de Emalhe e o Efeito nas Taxas de Captura Acidental de Toninhas, Pontoporia blainvillei (Cetacea, Pontoporiidae), na Costa Sul do Rio Grande do Sul. Tese de Mestrado. FURG - Rio Grande/RS. 140p.

HAIMOVICI, M. 1997. Recursos Pesqueiros Demersais da Região Sul. FEMAR. Rio de Janeiro. 80p.

KINAS, PG 2002. The impact of incidental kills by gillnets on the franciscana dolphin (Pontoporia blainvillei) in southern Brazil. Bull. Mar. Sci. 70 (2):409-421.

KINAS, PG \& ER SECCHI. 1998. Modelling truncated data to estimate incidental kills of franciscana, Pontoporia blainvillei, by illnets. Rep. Int. Whal. Commn. 48:533-536.

LAMMARDO, MP. 2002. Análise das tendências dos comprimentos totais da franciscana (Pontoporia blainvillei) nos encalhes de praia no Rio Grande do Sul (1979-2000). Disertação de Bacharelado. Fundação Universidade do Rio Grande. Rio Grande - RS. 56p.

LEENEY RH, R AMIES, ACBRODERICK, MJ WITT, J LOVERIDGE, J DOYLE \& BJ BODLEY. 2008. Spatio-temporal analysis of cetacean strandings and bycatch in a UK fisheries hotspot. Biodiversity and Conservation. Biodiversity Conserv. 17:2323-2338.
MORENO, IB, PH OTT \& D DANILEWICZ. 1997. Análise preliminar do impacto da pesca artesanal costeira sobre Pontoporia blainvillei no litoral norte do Rio Grande do Sul,sul do Brasil. p.31-41. in: Pinedo, M.C. e Barreto, A. (Eds) Proceedins of the Second Workshop for the Research Coordination and Conservation of the franciscana (Pontoporia blainvillei) in the Southwestern Atlantic. Rio Grande. 88p.

OTT, PH, ER SECCHI, IB MORENO, D DANILEWICZ, EA CRESPO, P BORDINO, R RAMOS, AP DI BENEDITTO, C BERTOZZI, R BASTIDA, R ZANELATTO, J PEREZ \& PG KINAS. 2002. Report of the working group of fishery interactions. The Lat. Am. J. Aquatic Mamm. (special issue) 1:55-64.

PALMA, ED, R MATANO \& AR PIOLA. 2008. A numerical study of the Southwestern Atlantic Shelf circulation: Stratified ocean response to local and offshore forcing. J. Geophys. Res. 113, C11010.

PINEDO, MC \& T POLACHEK. 1999. Trends in franciscanas (Pontoporia blainvillei ) strandings rates in Rio Grande do Sul, Southern Brazil (1979-1998). J. Cetacean Res. Manage. 1:179-789. PIOLA, AR, RP MATANO, ED PALMA, OO MÖLLER JR. \& EJD CAMPOS. 2005. The influence of the Plata River discharge on the western South Atlantic shelf, Geophys. Res. Lett., 32.

PRADERI, R. 1997. Análisis comparativo de estadísticas de captura y mortalidad incidental de Pontoporia blainvillei en Uruguay durante 20 años. In M. Pinedo \& A. Barreto, editores, Anais do 20. Encontro sobre a Coordenação de Pesquisa e Manejamento da Franciscana, pags. 42-53. University of Rio Grande, Brazil.

PRADERI, R, M PINEDO \& E CRESPO. 1989. Conservation and management of Pontoporia blainvillei in Uruguay, Brazil and Argentina. In 3 Occas. Pap. IUCN SSC, editor, Biology and Conservation of the River Dolphins., pags. 52-56. IUCN.

PRADO, J HF. 2006. Estimativa da taxa de encalhe das toninhas, Pontoporia blainvillei, capturadas acidentalmente na pesca com rede de emalhe, na costa sul do Rio Grande do Sul. Dissertação de Bacharelado, Fundação Universidade Federal do Rio Grande, Rio Grande, RS.

$R$ DEVELOPMENT CORE TEAM. 2008. R: a language and environment for statistical computing. R Foundation for Statistical Computing. Viena. Disponível em http://www.R-project.org.

REIS, EG, PC VIEIRA \& VS DUARTE. 1994. Pesca artesanal de teleósteos no estuário da Lagoa dos Patos e costa do Rio Grande do Sul. Atlântica 16:55-68.

SECCHI ER. 1999. Taxa de crescimento potencial intrínseco de um estoque de franciscanas, Pontoporia blainvillei (Gervais \& D`Orbigny, 1846) (Cetácea, Pontoporiidae) sob o impacto da pesca costeira de emalhe. Dissertação de Mestrado. FURG_RS. Rio Grande. 152 pp.

SECCHI, ER. 2006. Modelling the population dynamics and viability analysis of franciscana (Pontoporia blainvillei) and Hector's dolphins (Cephalorhynchus hectori) under the effects of bycatch in fisheries, parameter uncertainty and stochasticity. Tese de Doutorado. University of Otago, Dunedin, NZ. 252pp.

SECCHI ER, AN ZERBINI, M BASSOI, L DALLA ROSA, LM MOLLER \& CC ROCHA-CAMPOS. 1997. Mortality of franciscanas, Pontoporia blainvillei, in coastal gillnetting in southern Brazil: 19941995. Rep. Int. Whal. Commn 47:653-8.

SECCHI, ER \& PH OTT. 2000. A profundidade como um fator determinante da distribuição de toninhas, Pontoporia blainvillei, conforme indicado pelos índices de CPUE. Report of the third 
Workshop for Coordinated Research and Conservation of the Franciscana Dolphin (Pontoporia blainvillel) in the Southwestern Atlantic. Unep/CMS,Bonn. p. 55-57.

SECCHI, ER, PH OTT, EA CRESPO, PG KINAS, SN PEDRAZA \& $P$ BORDINO. 2001. A first estimate of franciscana (Pontoporia blainvillei) abundance off southern Brazil. J. Cetacean. Res. Manage. 3:95-100.

SECCHI, E, D DANILEWICZ, PH OTT, R RAMOS, M LAZARO, J MARIGO, \& JY WANG. 2002. Report of the working group on stock identity. The Latin American Journal of Aquatic Mammals. 1(1):47\{54.

SECCHI, ER, D DANILEWICZ. \& PH OTT. 2003a. Applying the phylogeographic concept to identify franciscana dolphin stocks: implications to meet management objectives. J. Cetacean. Res. Manage. 5:61-68.

SECCHI, ER, PH OTT \& DS DANILEWICZ. 2003b. Effects of fishing by-catch and conservation status of the franciscana dolphin, Pontoporia blainvillei. In GALES, N, M HINDELL \& R KIRKWOOD. (Eds) Marine Mammals: Fisheries, Tourism and Management Issues. CSIRO Publishing. Collingwood. Australia. Pages 174-191
SECCHI, ER, PG KINAS \& M MUELBERT. 2004. Incidental Catches Of Franciscana In Coastal Gillnet Fisheries In The Franciscana Management Area III: Period 1999-2000. The Lat. Am. J. Aquatic Mamm.. LAJAM 3(1): 61-68.

SEELIGER, U, C ODEBRECHT \& JP CASTELLO. 1997. Subtropical Convergence Environments - The Coast and Sea in the Southwestern Atlantic. Germany. Ed. Springer. 308 pp.

SICILIANO, S. 1994. Review of small cetaceans and fishery interactions in coastal waters of Brazil. Reports of the International Whaling Commission., special issue(15), 241-250.

SOARES, I \& OO MÖLLER JR. 2001. Low-frequency currents and water mass spatial distribution on the southern Brazilian shelf. Cont. Shelf. Res. 21: 1785-1814.

STANBURY, KB \& RM STARR, 1999. Applications of Geographic Information Systems (GIS) to habitat assessment and marine resource management. Oceanol. Acta. 6(22): 699-703.

WALKER .RJ, EO KEITH E, AE YANKOVSKY \& DK ODELL. 2005. Environmental correlates of cetacean mass stranding sites in florida. Mar. Mamm, Sci. 21 (2). 327-335

ZAR, JH. 1999. Biostatistical analysis. Prentice-Hall, New Jersey.

Recebido: 30/10/2008

Aceito: $21 / 07 / 2010$ 


$$
\text { . }
$$

